\title{
Calculation of Greenland and Antarctica Glaciers' Weights Causing Some Earthquakes and Volcanic Activities
}

\begin{abstract}
A.Y. ÜRÜŞAN*, T. UZEL AND K. EREN
Istanbul Kultur University, Geomatic Application and Research Center (GARC), Atakoy Kampusu E5 Karayolu Uzeri D100 Yanyol, 34156 Bakirkoy, Istanbul, Turkey

Global warming is very important subject for environmental physics. Although the earth seems like inanimate, it acts just like a live mechanism which is called as Glacial-Interglacial Ice. One can consider that there are three periods for this forming, say major (100,000 years), minor (12,000 years) and smaller (1000 years) ice ages. The temperature of the earth is affected by increasing especially $\mathrm{CO}_{2}$ and other sera gases in the atmosphere. The solar radiation reflected from the earth surface cannot go back to the space due to the sera gases and is absorbed by the atmosphere. After the industrial revolution at the beginning of 20th century, especially in the last 30 years, the amount of $\mathrm{CO}_{2}$ and the other carbon gases emitted into the atmosphere has been increasing and causing natural disasters like irregular local temperature changes, floods, melting glaciers, and more powerful hurricanes. The solar radiations are mostly reflected by glaciers which are significant formations on the earth. Melting of these glaciers reduces the surface reflection and causes more absorption of solar radiation by the earth. In addition, sea level, amount of fresh water, and perceptible water vapor in the atmosphere may increase. In this study, Greenland and Antarctica glaciers' weights which press the plates downward are calculated. Melting the glaciers, the plates get rid of the pressure and rise upward over the mantle, and may cause some earthquakes, and volcanic activities such as Thoku earthquake in Japan and Eyjafjallajökull and Grimsvötn volcanos in Iceland.
\end{abstract}

DOI: 10.12693/APhysPolA.125.521

PACS: 96.12.Kz, 91.30.Px, 92.70.-j, 93.30.Kh

\section{Introduction}

Large continental ice sheets in the World have grown and shrunk several times in the past. Although the earth seems like inanimate, it acts just like a live mechanism, which is called Glacial-Interglacial Ice age. One can consider that there are three periods for this forming, say major (100,000 years), minor (12,000 years) and smaller (1000 years) ice ages. Generally, times with and without large ice-sheets are known respectively as glacial periods (or ice ages) and interglacial periods, respectively. Some important researchers give plenty of information about differences from Glacial to Interglacial period like solar radiation in July, temperature and atmospheric $\mathrm{CO}_{2}$ changing in time at Dome Fuji, Antarctica [1].

The cause of glacial-interglacial cycles is based on $\mathrm{CO}_{2}$, water vapor and other greenhouse gases amount in earth atmosphere. The earth absorbs solar energy and reflects some of that energy to space. Earth's surface temperature increases due to these greenhouse gases which alter the return of energy to space (Fig. 1). Thus, the lower atmosphere and the earth's surface warm up [2].

Surface temperature is important for life on Earth. The Earth surface temperature is kept on approximately $32{ }^{\circ} \mathrm{C}$ by greenhouse effect in long term for annual period. Greenhouse gases occur naturally in the Earth atmosphere. However, the amount of $\mathrm{CO}_{2}$ and the other carbon gases are emitted from 300 to 380 ppm into the atmo-

*corresponding author; e-mail: a.urusan@iku.edu.tr

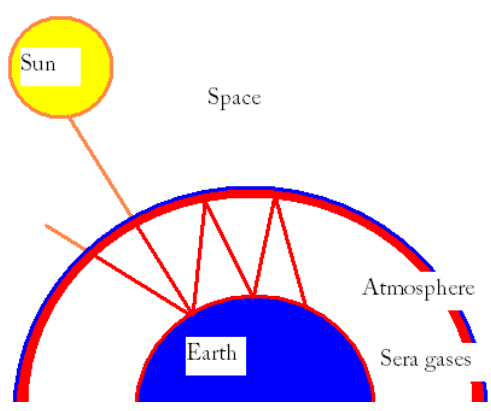

Fig. 1. The greenhouse effect.
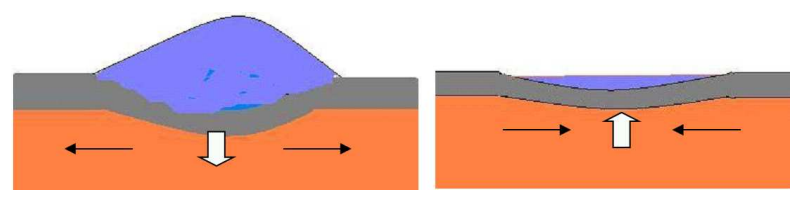

Fig. 2. Mantle and crustals' behaviour in glacial-interglacial time.

sphere. The average temperature has increased approximately $0.7^{\circ} \mathrm{C}$ after the industrial revolution at the beginning of 20 th century, especially in the last 30 years [2]. Finally, the human activities have affected the greenhouse gases amount in the atmosphere in last years, hence influencing their lives in a negative manner [3].

\section{Deglaciation time}

Due to global warming, number and magnitude of natural disasters like irregular local temperature changes, 
floods, melting glaciers, and more powerful hurricanes have increased. Specially, this case causes significant effects on vertical and horizontal crustal motion, earthquakes, gravity field, and Earth's rotational motion. Glacier melting has caused highly significant changes to coastlines and landscapes. Finland is witnessing crustal rising, the Northern Britain is rising up to $10 \mathrm{~cm}$ per century, but southern of half of the island is moving downward about $5 \mathrm{~cm}$ per century [4]. This will create risk of floods in southern England and south-western Ireland.

Also, in deglaciation time, the melted ice water returning to the oceans increases and sea level, too, but not at the same level everywhere. This depends on gravitation and centrifugal potential due to Earth's variable rotation [4].

There is also horizontal motion of the crust moving through vertical motion time (Fig. 2). This motion usually diverges from the center of rebound. This looks like a big part of the cork released in water. The cork rises up and shakes when the downward pressure is removed. However, the cork hits and applies pressure and creates stress to the other corks like plates on the mantle of the earth. Thus, the big magnitude earthquakes occur on the earth's surface. Horizontal and vertical motions change the tilt of the surface like island of Great Britain and North America [4, 5].

Gakkel Ridge is between North American Plate and Eurasian Plate on the North Pole. Large number of earthquake activities occurred after 1970, especially, between 1999 and 2000 (more than 250). The chart in [6] shows how the earthquake number is rising along the Gakkel Ridge. This ridge is integrated with mid-Atlantic ridge lying at the Eurasia plate. It can trigger some earthquakes like Thoku in the Pacific Ocean and extend to the Philippines plate by cutting the Eurasia plate during the melting time Greenland Glaciers.

The Mid-Atlantic Ridge extends from Iceland to the South pole along the Atlantic ocean. Some important volcano activities occurred on or near the ridge like Eyjafjallajökull and Grimsvötn volcanos in Iceland [7].

Earthquakes and volcanic activities are mostly on plate boundaries throughout the world [8]. We may consider them in two important groups: (i) the Greenland, Iceland, Ireland and Great Britain countries and the Mid-Atlantic Ridge and the Gakkel Ridge are in the same group, (ii) the other group includes potential active fault which cuts the Eurasia plate, between the Gakkel Ridge and the Pacific Ridge.

\section{Applications}

In this section of paper, Greenland and Antarctica glaciers' weights, which press the plates downward, are calculated by Newton law (2). At first, the glaciers' masses are calculated using density formula (1).

\subsection{Greenland glaciers' weight}

Glacier flat surface $=1,710,000 \mathrm{~km}^{2}$, and ice-sheet height $=2135-3000 \mathrm{~m}$, volume $=1.710 \times 10^{9} \times 2.135=$ $3.650850 \times 10^{9} \mathrm{~m}^{3}, 1 \mathrm{~m}^{3}=1000 \mathrm{~L} \rightarrow \approx 3.650850 \times$ $10^{12} \mathrm{~L} \rightarrow \approx 3.650850 \times 10^{15}$ and density of ice $=0.92 \mathrm{~g} / \mathrm{ml}$

$$
\text { density }=\frac{\text { mass }}{\text { volume }}[\mathrm{g} / \mathrm{ml}] \text {. }
$$

Mass $=$ density $\times$ volume; glacier mass $=0.92 \times 3.651 \times$ $10^{21} \mathrm{ml}$; glacier mass $=3.359 \times 10^{21} \mathrm{~g} \rightarrow 3.359 \times 10^{15}$ ton .

$$
\text { weight }=m \times g[\mathrm{~N}] \text {. }
$$

Glaciers' weight $=9.832 \mathrm{~m} / \mathrm{s}^{2} \times 3.359 \times 10^{18} \mathrm{~kg}=$ $33.03 \times 10^{18} \mathrm{~kg} \mathrm{~m} / \mathrm{s}^{2}[\mathrm{~N}]$.

\subsection{Antarctica glaciers' weight}

Glacier flat surface $=14 \times 10^{6} \mathrm{~km}^{2}$, and volume $=$ $30 \times 10^{6} \mathrm{~km}^{3}$; glaciers' mass $=27.6 \times 10^{15}$ ton; glaciers' weight $=271.36 \times 10^{18} \mathrm{~N}$.

\section{Conclusions}

Greenland and Antarctica glaciers' weights which press the plates downward are calculated. It shows that there is a big downward pressure on the Greenland and Antarctica by ice-sheets. During melting, the plates release pressure and rise upward over the mantle like a cork in water. This natural event may cause some big magnitude earthquakes and more volcanic activities near or on the Mid-Atlantic Ridge and the Gakkel Ridge in northern hemisphere and all adjacent plates to the Antarctica plate in southern hemisphere.

Sea level will be increased by the returned ice water during melting time. Since the sea level depends on gravitation and centrifugal potential due to Earth's variable rotation, it will not be at the same level everywhere.

Melting of the Greenland glacier may trigger a newer potential active fault between Gakkel Ridge and Pacific Ridge.

\section{References}

[1] http://www.ncdc.noaa.gov/paleo/abrupt/data2. html.

[2] http://www.ncdc.noaa.gov/paleo/globalwarming/ what.html .

[3] http://www.kent.gov.uk/environment_and_ planning/environment_and_climate_change/ climate_change/what_is_climate_change.aspx .

[4] http://en.wikipedia.org/wiki/Isostatic_ rebound.

[5] E. Wolin, S. Stein, F. Pazzaglia, A. Meltzer, A. Kafka, C. Berti, Geophys. Res. Lett. 39, L02305 (2012).

[6] http://arctic-news.blogspot.com/p/ runaway-warming.html .

[7] http://en.wikipedia.org/wiki/Mid-Atlantic_ Ridge .

[8] http://staff.imsa.edu/science/si/horrell/ materials/Earthquakes/quakes6.html . 